\title{
Durability Evaluation of Hemp Fibers and Recycled Aggregates Concrete
}

\author{
Samer Ghosn ${ }^{1}$ and Bilal Hamad ${ }^{2}$ \\ ${ }^{1}$ Department of Civil and Environmental Engineering, American University of Beirut, P.O. Box 11- \\ 0236 Riad El Solh 1107-2020, Beirut, Lebanon; ssg13@mail.aub.edu \\ 2 Department of Civil and Environmental Engineering, American University of Beirut, P.O. Box 11 - \\ 0236Riad E1 Solh 1107-2020, Beirut, Lebanon; bhamad@aub.edu.lb
}

\begin{abstract}
Hemp and Recycled Aggregates Concrete (HRAC) is a sustainable concrete where coarse aggregates are partially replaced with industrial hemp fibers and recycled concrete aggregates (RCA). This replacement has two main benefits: it saves on natural resources and it recycles and reuses waste material. Previous studies showed that the mechanical performance of HRAC is satisfactory. On the other hand, concrete's durability is also an important criterion to evaluate concrete's performance and HRAC's durability can be affected by the presence of both RCA and hemp fibers in the concrete's alkaline environment. This paper aims at investigating the durability of HRAC concrete mixes by comparing the mechanical performance of HRAC specimens at the ages of 2 and 28 days. Furthermore, the performance of HRAC under freeze/thaw cycles is evaluated and compared to that of regular concrete. Results showed that the mechanical performance of HRAC improves at older age and the resistance of HRAC mixes to freeze-thaw cycles is similar to that of control mixes.
\end{abstract}

Keywords: Sustainable Concrete Materials, Recycled Aggregates, Hemp Fibers, Durability, Mechanical Properties.

\section{Introduction and Background}

Sustainability has become an essential issue on a global scale in the recent years. Therefore, construction, among other sectors, is reviewing its practices to make them more environmentally friendly and reduce their negative effect on the planet as a whole.

Concrete production consumes large quantities of natural aggregates causing significant damage to the environment. To reduce the amount of natural aggregates used in concrete HRAC is proposed. This is a concrete mix where hemp fibers are incorporated in the mix, the amount of natural coarse aggregates (NCA) is reduced by $20 \%$, and where $50 \%$ of NCA are replaced by RCA.

HRAC also helps in reducing the problem of construction and demolition wastes (CDW) which are a mixture of surplus materials generated during new construction, renovation, and demolition of buildings, roads, bridges, and other structures (Cheng et al., 2013)

A sustainable concrete should be also durable; therefore, it is important to study the effect of the incorporation of hemp fibers and RCA on the durability properties of concrete.

Ramli et al. (2013) studied the durability of coconut-fiber-reinforced concrete in aggressive environments. Results showed that the damaging effects of aggressive environments on concrete can be lowered with fiber-reinforced concrete since the fibers play a role in restraining the development of cracks. Awwad et al. (2014) investigated the longterm behavior of concrete incorporating hemp fibers and concluded that at an age of 1.5 years 
hemp fibers did not have a negative effect on concrete strength. Vázquez et al. (2014) found that the presence of RCA in concrete can improve the resistance to chloride penetration since $\mathrm{C}-\mathrm{S}-\mathrm{H}$ gels that exist in higher amounts in RCA assist in chloride binding. Also, the resistance of high-performance concrete with RCA to freezing can be similar to that of normal concrete (Ajdukiewicz et al., 2002). The carbonation depth increases with the increase of RCA replacement ratio, but Lei et al. (2008) found that when the percentage replacement of NCA with RCA was higher than $70 \%$, the carbonation depth decreased, which may be due to the adhered mortar on the RCA which increases the total cement content and slows down the carbonation rate.

In this paper, the durability of the proposed HRAC is investigated by evaluating its mechanical performance at the age of 2 years and by studying its resistance to freeze-thaw cycles.

\section{Materials and Experimental Procedures}

Sixteen different mixes were prepared and are identified in Table 1. The mixes are divided into two groups: Group 1 with MSA of $10 \mathrm{~mm}$ and Group 2 with MSA of $20 \mathrm{~mm}$. The control mixes with no hemp fibers and no coarse aggregate reduction are referred to as N10 (NCA with $\mathrm{MSA}=10 \mathrm{~mm}$ ) and $\mathrm{N} 20(\mathrm{NCA}$ with $\mathrm{MSA}=20 \mathrm{~mm}$ ), and were designed to achieve a concrete compressive strength of $30 \mathrm{MPa}$. R10 and R20 are two mixes with 50 percent replacement of NCA with RCA, no hemp fibers, and also no reduction of coarse aggregate

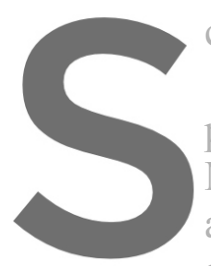
content.

\section{The other twelve nix} part is $\mathrm{N}(100 \% \mathrm{NCA})$

MSA. The second part and $\mathrm{H} 30$ is $30 \mathrm{~mm}$.
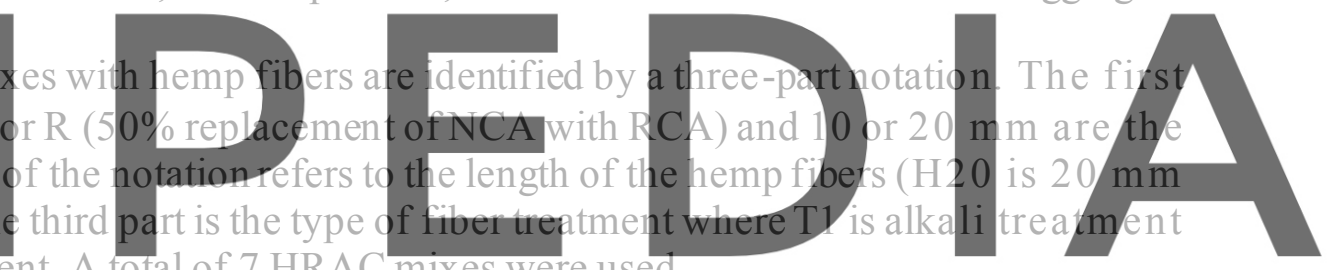

and T2 is acetyl treatment. A total of 7 HRAC mixes were used.

Based on the reported studies of Awwad etal. (2014), hemp fib.ers in mixes with fibers

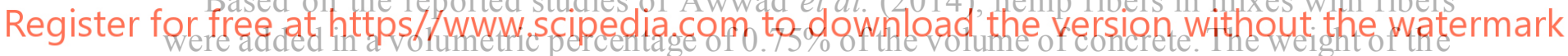

fibers was then calculated based on the average density of the fibers determined to be 1,400 $\mathrm{kg} / \mathrm{m}^{3}$. The weight of the coarse aggregates for these mixes was also reduced by $20 \%$ of the concrete volume.

To study the long-term mechanical performance of HRAC, compressive strength tests, flexural strength tests and modulus of elasticity tests were performed at an age of 2 years for 14 of the 16 mixes and the results were compared to the results at 28 days presented in previous studies (Ghosn et al., 2019). The tests were done according to ASTM C39 (2017), ASTM C78 (2016) and ASTM C469 (2014) respectively. For each test, 2 replicates were made for each mix.

The resistance to freeze-thaw cycles was conducted according to ASTM C666 (2015). For each mix, one prismatic specimen $(75 \times 100 \times 405 \mathrm{~mm})$ was cast and cured in water for 28 days. Each specimen was then brought to a temperature of $-18{ }^{\circ} \mathrm{C}$ and tested for fundamental transverse frequency. Then, the specimens were exposed to 144 cycles of freezing and thawing. Each freezing-and-thawing cycle consisted of lowering the temperature of the specimens from 4 to $-18{ }^{\circ} \mathrm{C}$ and raising it from -18 to $4{ }^{\circ} \mathrm{C}$ in a period of 4 hours and 40 minutes. 
Table 1. Identification of the concrete mixes.

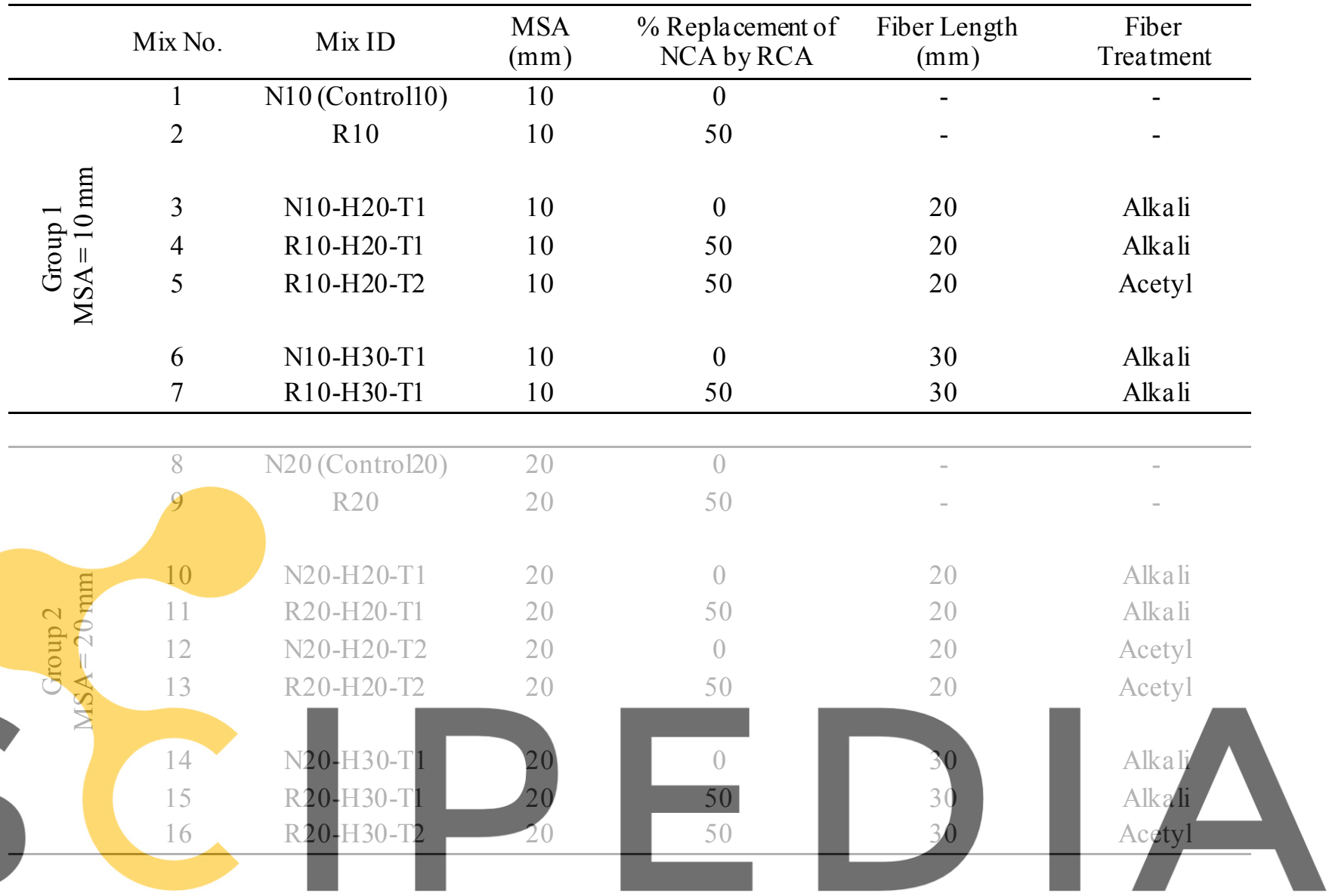

The specimens were tested for their fundamental transverse frequency each 36 cycles. The

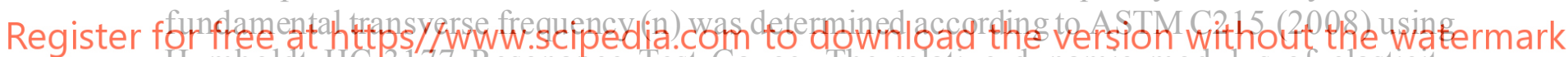
Humboldt HC-317 Resonance Test Gauge. The relative dynamic modulus of elasticity

(RDME) was then calculated as follows:

$$
P_{c}=\frac{n_{1}^{2}}{n^{2}} \times 100
$$

Where: $P_{c}=$ Relative dynamic modulus of elasticity (RDME) after c cycles of freezing and thawing (\%), $\mathrm{n}$ is the fundamental transverse frequency before proceeding freezing and thawing cycles, and $n_{1}$ is the fundamental transverse frequency after c cycles of freezing and thawing.

For each test two groups of specimens were tested: Group 1 with MSA of $10 \mathrm{~mm}$ and Group 2 with MSA of $20 \mathrm{~mm}$. In each group, normal and recycled aggregate mixes $(\mathrm{N}$ and $\mathrm{R}$ mixes) with or without hemp fibers and with different fiber lengths and fiber treatments were tested and compared. 


\section{Results and Discussion}

\subsection{Long-Term Mechanical Performance}

\subsubsection{Compressive strength}

The results of the compressive strength test are presented in Table 2.

Table 2. Compressive strength testresults.

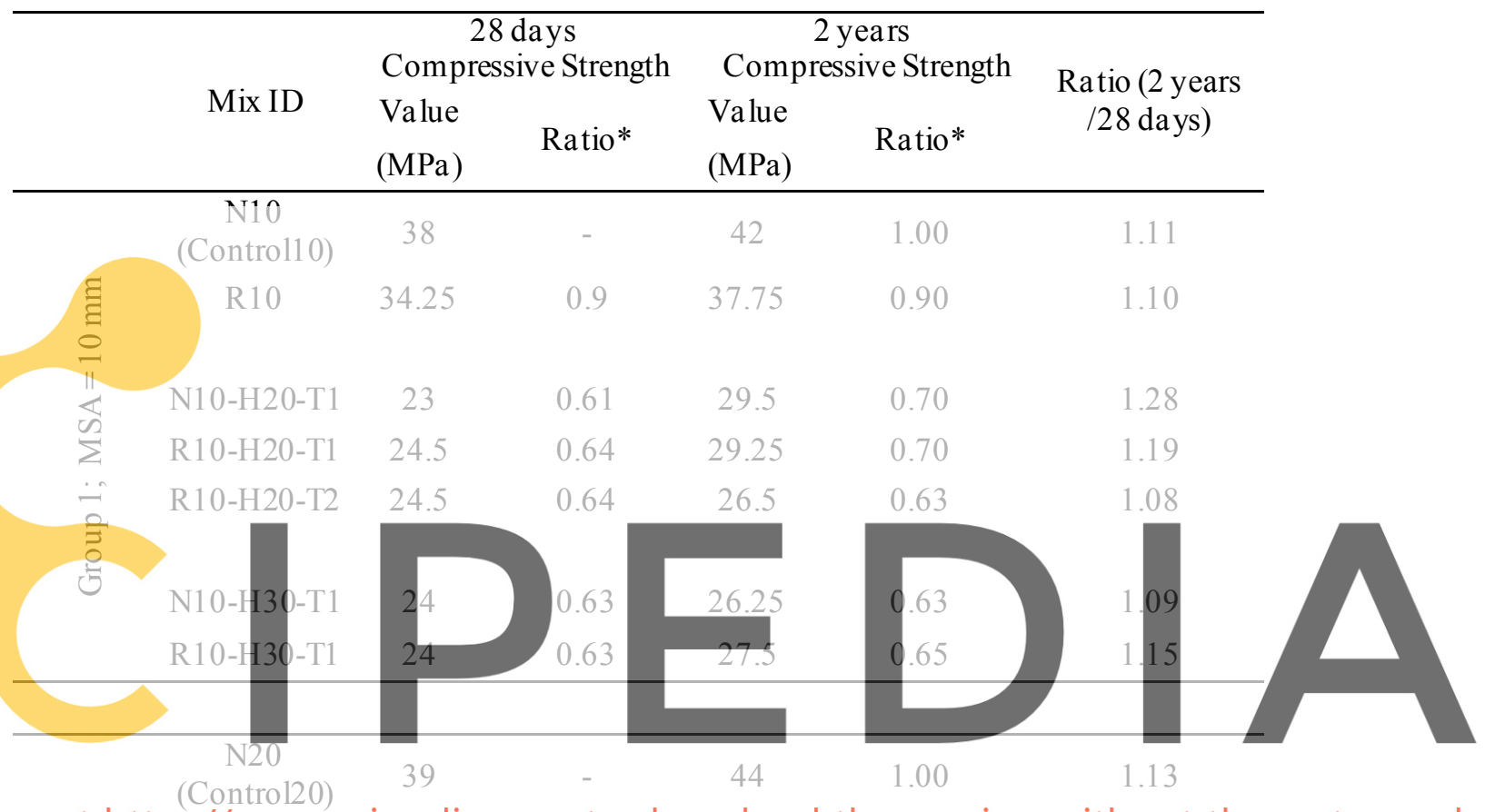

Register for free atzhttps//Mwbw.scipejdia.com to download the version withqut the watermark

\begin{tabular}{|c|c|c|c|c|c|}
\hline N20-H20-T1 & 28 & 0.72 & 34 & 0.77 & 1.21 \\
\hline $\mathrm{R} 20-\mathrm{H} 20-\mathrm{T} 1$ & 25 & 0.64 & 31.5 & 0.72 & 1.26 \\
\hline $\mathrm{N} 20-\mathrm{H} 30-\mathrm{T} 1$ & 32 & 0.82 & 34 & 0.77 & 1.06 \\
\hline R20-H30-T1 & 26 & 0.67 & 31.25 & 0.71 & 1.20 \\
\hline R20-H30-T2 & 25 & 0.64 & 32.75 & 0.74 & 1.31 \\
\hline
\end{tabular}

$*$ Ratio $=$ Mechanical property value for the mix divided by that of the control mix N10 in Group 1 and by that of the controlmix N20 in Group 2.

In general, the results at the age of 2 years were consistent with results at the age of 28 days; when the hemp fibers are incorporated in the mix, the compressive strength decrease $s$ since aggregates which are the hardest elements in a concrete mix are replaced by fibers which are weak in compression. Furthermore, all mixes showed an improved compressive 
strength at the age of 2 years as compared to those at the age of 28 days. This increase ranges from 6 up to $31 \%$ for the HRAC mix R20-H30-T2.

\subsubsection{Flexural strength}

The results of the flexural strength test are presented in Table 3.

Table 3. Flexural strength test results.

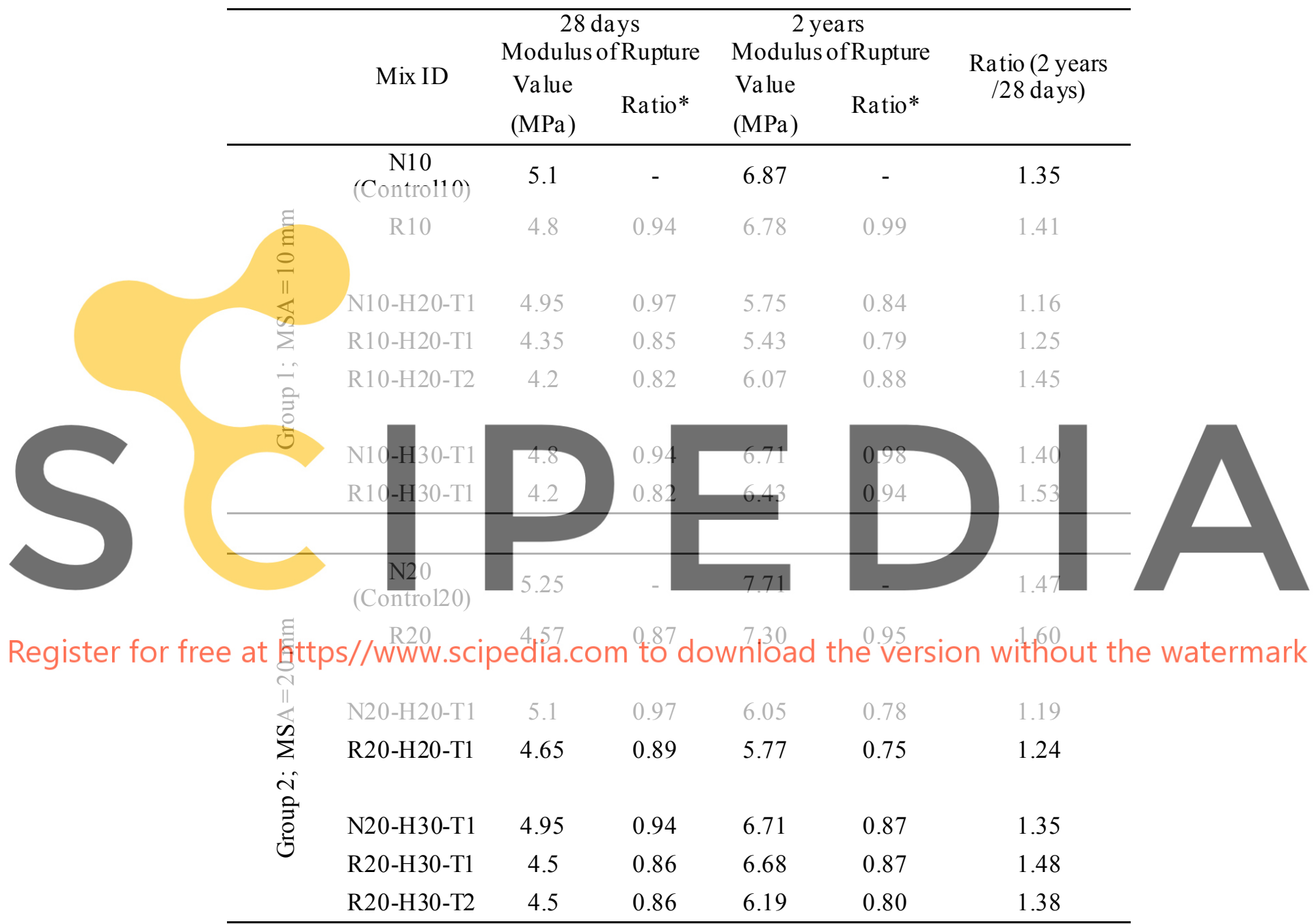

$*$ Ratio $=$ Mechanical property value for the mix divided by that of the control mix N10 in Group 1 and by that of the controlmix N20 in Group 2.

The variation of the flexural strength at the age of 2 years is consistent with that at the 28 days; the incorporation of hemp fibers and recycled aggregates leads to lower flexural strength. However, this decrease is less significant as compared to that in the compressive strength as some HRAC mixes have a flexural strength of $94 \%$ compared to the that of the control mix at the age of 2 years. In addition, the flexural strength shows a significant increase at the age of 2 years with increases around $50 \%$ in some of the HRAC mixes. 


\subsubsection{Modulus of Elasticity}

The results of the flexural strength test are presented in Table 4.

Table 4. Modulus of ela sticity test results.

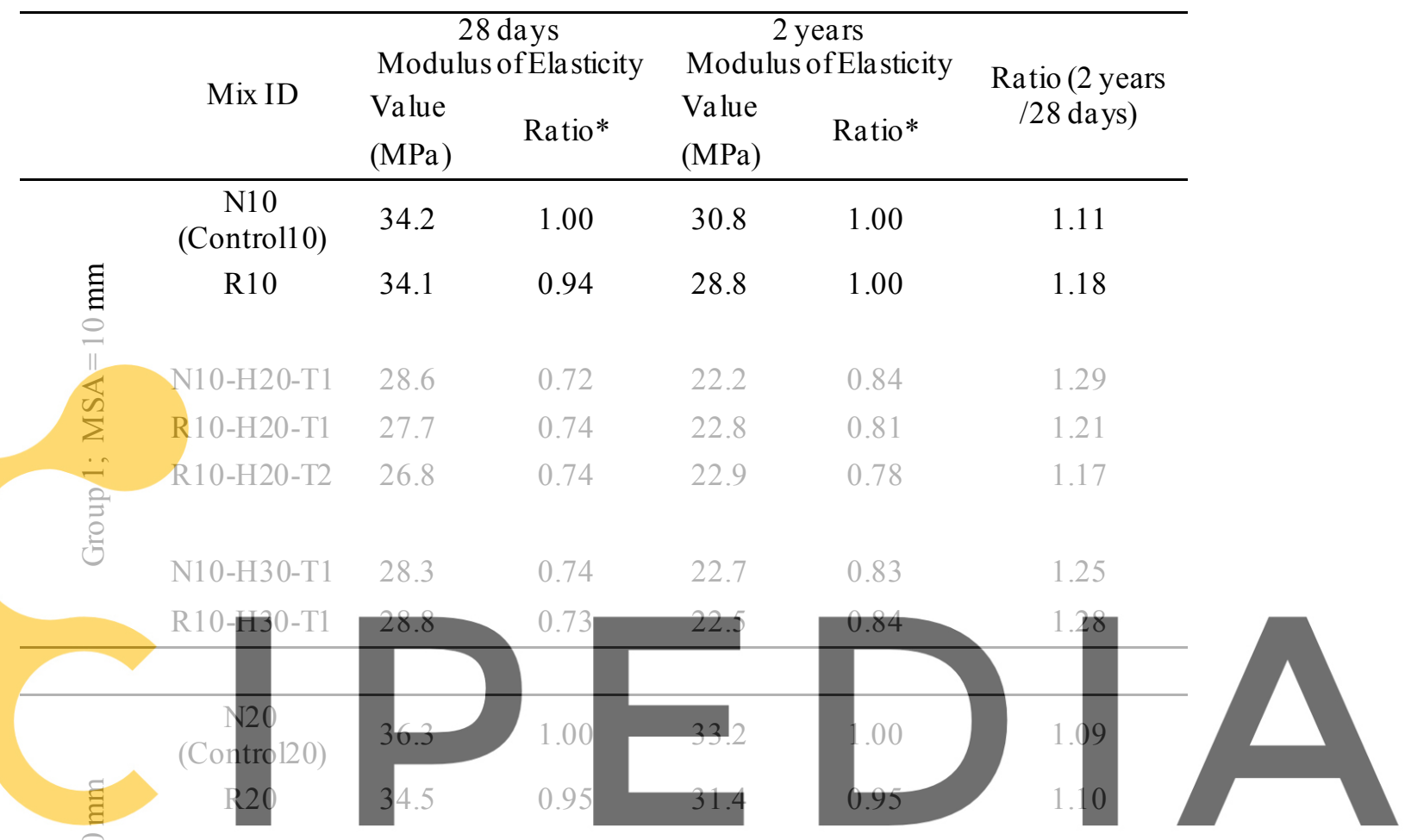

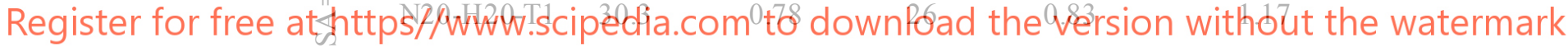
言 R20-H20-T1 28. $\begin{array}{lll}0.71 & 23.7 & 0.80\end{array}$ 1.22

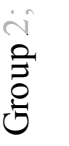

$\begin{array}{llllll}\text { N20-H30-T1 } & 28.6 & 0.82 & 27.2 & 0.79 & 1.05 \\ \text { R20-H30-T1 } & 25.5 & 0.73 & 24.3 & 0.70 & 1.05 \\ \text { R20-H30-T2 } & 25.7 & 0.71 & 23.7 & 0.71 & 1.08\end{array}$

$*$ Ratio = Mechanical property value for the mix divided by that of the control mix N10 in Group 1 and by that of the controlmix N20 in Group 2.

Similar to the compressive strength, the MOE is also higher at the age of 2 years than at the age of 28 days. The increase ranges between 5 and $28 \%$ for HRAC mixes. 


\subsection{Resistance to Freeze/Thaw Cycles}

Results of Pc or RDME after each 36 cycles of freezing and thawing are presented in Table 5. Group 1 with MSA of $10 \mathrm{~mm}$, had a good resistance to freeze-thaw cycles for all tested specimens with Pc ranging from $77 \%$ to $90.4 \%$ after 144 cycles. While Pc for the recycled aggregate mix R10 was the lowest in the group (77\%), mixes with hemp fibers had a Pc ranging between 77 and 90.4, a value which is even higher than the control mix (83.5\%).

Group 2 mixes with MSA of $20 \mathrm{~mm}$, had a lower resistance to freeze-thaw cycles than that of Group 1 mixes. Pc decreased more quickly to reach values ranging between $31 \%$ and $56.5 \%$ after 144 cycles. Similar to Group 1, 50\% replacement of NCA with RCA but with out hemp fibers incorporation (R20) led to the lowest value of Pc after 144 cycles (31\%). This poor resistance of Group 2 to freeze-thaw cycles can be due to the fact that when the MSA increases from 10 to $20 \mathrm{~mm}$, the cement matrix contains less entrapped air bubbles. During the freezing phase of a cycle, the water present in the matrix freezes and expands causing pressure that may lead to cracks and to the deterioration of the concrete. The more entrapped air bubbles present in the $10-\mathrm{mm}$ matrix relieves the pressure by providing more space for water to expand into when it freezes. As for the effect of incorporating hemp fibers in the mix, the four mixes with hemp fibers had values ranging between 42 and $56.5 \%$ as compared with $51 \%$ for the control mix N20.

Table 5. Rela tive dynamic m odulus of elasticity (RDME) values of a 11 mix es after each
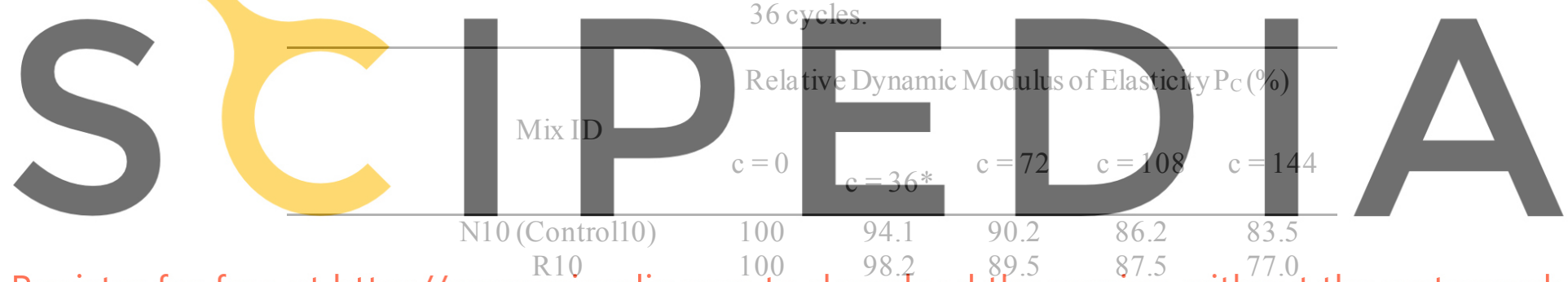

Register for free at htłps//www.scipedia.com to downitoad the version without the watermark

\begin{tabular}{|c|c|c|c|c|c|c|}
\hline \multirow{5}{*}{ 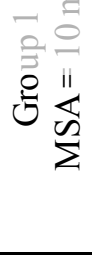 } & N10-H20-T1 & 100 & 93.8 & 87.2 & 81.6 & 77.0 \\
\hline & R10-H20-T1 & 100 & 90.5 & 90.5 & 90.5 & 88.5 \\
\hline & R10-H20-T2 & 100 & 90.2 & 88.5 & 83.7 & 79.5 \\
\hline & N10-H30-T1 & 100 & 95.2 & 93.0 & 93.0 & 90.4 \\
\hline & R10-H30-T1 & 100 & 95.2 & 93.0 & 90.4 & 90.4 \\
\hline \multirow{6}{*}{ 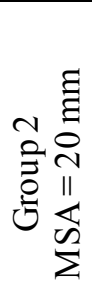 } & N20 (Control20) & 100 & 93.2 & 79.2 & 62.4 & 51.0 \\
\hline & R20 & 100 & 92.7 & 70.2 & 57.8 & 31.0 \\
\hline & N20-H20-T1 & 100 & 88.1 & 79.2 & 70.8 & 42.0 \\
\hline & N20-H20-T2 & 100 & 83.2 & 75.3 & 63.7 & 55.5 \\
\hline & R20-H20-T2 & 100 & 85.8 & 78.3 & 69.5 & 53.2 \\
\hline & R20-H30-T1 & 100 & 87.7 & 77.2 & 70.5 & 56.5 \\
\hline
\end{tabular}

$*_{c}=$ number offreeze-thaw cycles. 


\section{Conclusion}

This paper studies the durability and long-term performance of HRAC, a "green" concrete material where natural aggregates are partially replaced by recycled concrete aggre gates and industrial hemp fibers. Results showed that at the age of 2 years, HRAC mixes have an improved mechanical performance as compared to the age of 28 days, The compressive strength, the flexural strength and the modulus of elasticity improved by up to $31 \%, 53 \%$ and $28 \%$, respectively. The variation in the mechanical performance between HRAC mixes and control mixes was also consistent at the age of 28 days and the age of 2 years. Furthermore, the resistance to freeze-thaw cycles of HRAC was similar to that of normal concrete mixes after 144 cycles.

Based on these results, it can be concluded that HRAC is a durable concrete that has a reliable long-term mechanical performance and it can be used in cold climates as it has a freeze/thaw durability performance comparable to that of ordinary concrete mixes.

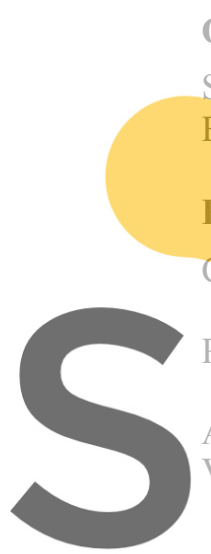

ORCIID

Samer Ghosn: http://orcid.org/0000-0002-0829-1311

Bila1Hamad: http://orcid.org/0000-0001-7057-573X

References

Cheng, J.C. and Ma, L.Y.(2013). A BIM-based system for demolition and renovation wa ste estimation a nd planning. Waste mana

Ramli, M.,Kwan,W.H. a ggressive environme

Awwad, E., Hamad, B., Mat

Vázquez, E., Barra, M., Ap with recycled aggregates
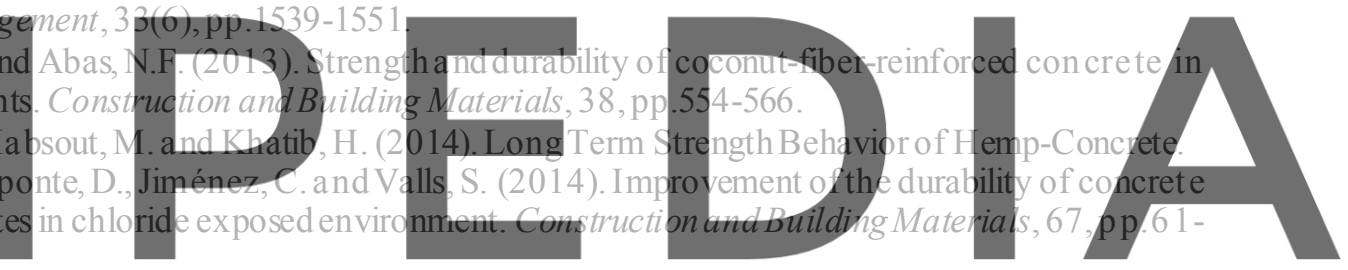

Ajdukiewicz, A. and Kliszczewicz, A. (2002). Influence of recycled aggregates on m ec han ical prop erties of

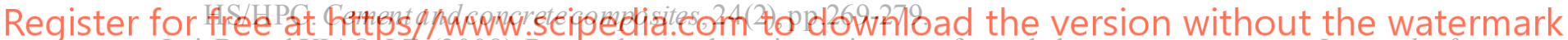

Lei, B. and XIAO,J.Z. (2008). Research on carbonation resistance of recycled aggregate concrete. Jo urnal of Building Materials, 5, pp. 605-611.

Awwad, E., Mia bsout, Mi., Hamad, B., Farran, Mi.T. and Khatib, H. (2012). Studies on fiber-reinforced concrete using industria lhemp fibers. Construction and Building Materials, 35, pp.710-717.

Ghosn, S., Cherkawi, N. and Hamad, B. (2019). Preliminary studies of hemp and recycled aggregate co ncrete. Academic Journal of Civil Engineering, 37(2), 520-524.

ASTM C666/C666M-15: (2015). Standard testmethod for resistance of concrete to rapid freezing and tha wing. ASTM International, West Conshohocken, PA.

ASTM C215 - 08: (2008). Standard test method for fundamental transverse, longitudinal, and torsional frequencies of concrete specimens. ASTMInternational, West Conshohocken, PA.

ASTM C39/C39M-18: (2018). Standard test method for compressive strength of cylindrical concrete specimens. ASTM International, West Conshohocken, PA.

ASTM C469/C469M-14: (2014). Standard testmethod for static modulus of ela sticity a nd po isson's ra tio of concrete in compression. ASTM International, West Conshohocken, PA.

ASTM C78/C78M-1 8: (2018). Standard test method for flexural strength of concrete (using simple beam with third-point loading). ASTM International, West Conshohocken, PA. 